\title{
O ensino de filosofia como ética do cuidado de si: experiências numa escola militar da região do extremo sul da Bahia
}

Philosophy teaching as self-care ethics: experiences in a military school in the extreme south of Bahia

Fábio Pereira Barros

Jair Miranda de Paiva

Resumo: Este texto tem por objetivo problematizar a filosofia e o seu ensino, destacando experiências filosóficas produzidas no Ensino Médio de um Colégio Militar. Mediante conceitos de Foucault, Larrosa, Cerletti, Kohan e Gallo, entre outros, buscamos pensar a filosofia na perspectiva do cuidado de si e da estética da existência. Como referencial metodológico, fazemos uso da pesquisa bibliográfica, bem como nos aproximamos do ambiente escolar com inspiração na perspectiva cartográfica de pesquisa como acompanhamento de processos e não de certezas pré-concebidas. Os resultados apresentam fragilidades quanto aos processos de ensino e aprendizagem em filosofia; por outro lado, apontam potencialidades de se promover experiências filosóficas criativas através do ensino e aprendizagem pautados na filosofia como ética do cuidado de si ou estética da existência, afirmando, dessa forma, que é possível um ensino de filosofia que produza experiências filosóficas críticas e criativas junto aos jovens.

Palavras-chave: Filosofia. Ensino. Militarismo. Estética da existência.

\begin{abstract}
This text aims to problematize philosophy and its teaching, highlighting philosophical experiences produced in high school at a military college. Through concepts by Foucault, Larrosa, Cerletti, Kohan and Gallo, among others, we seek to think of philosophy from the perspective of self-care and the aesthetics of existence. As a methodological reference, we make use of bibliographic research, as well as approaching the school environment with inspiration in the cartographic perspective of research as monitoring processes and not preconceived certainties. The results show weaknesses regarding the teaching and learning processes in philosophy; on the other hand, they point to the potential of promoting creative philosophical experiences through teaching and learning based on philosophy as ethics of self-care or aesthetics of existence, thus stating that it is possible to teach philosophy that produces critical and creative philosophical experiences with young people.
\end{abstract}

Keywords: Philosophy. Teaching. Militarism. Aesthetics of existence.

\section{Introdução}


Este artigo tem por objetivo investigar o ensino de filosofia como cuidado de si numa escola militar do sul da Bahia 1 . Inspirados na perspectiva cartográfica de pesquisa, buscamos fazer do percurso uma experiência de transformação de nós mesmos, consoante o desafio de pensar uma outra relação com a filosofia, problematizando nossa formação e práticas docentes.

Julgamos importante tal pesquisa porque se, de um lado, encontramos um ambiente hostil ao pensamento e à elaboração teórica em nossa época, marcada pelo movimento febril de imagens, de consumo e de concepções em crise (LIPOVETSKY, 2004), por outro lado, julgamos que a urgência de pensar exige alternativas para a educação em geral e, em especial para o ensino de filosofia (GALLO, 2012).

Em nossa investigação, buscaremos atingir nossos objetivos em partes interligadas: em primeiro lugar, uma reflexão, já desde esta introdução, sobre o lugar da filosofia no ensino nacional, articulada ao lugar de onde nos situamos; a seguir, tecemos breves considerações acerca do ensino de filosofia na perspectiva de uma ética do cuidado de si. Por fim, nos aproximamos de nosso campo de pesquisa, cartografando cenas da educação militarizada, ao mesmo tempo que nos propomos uma atividade de reflexão filosófica com discentes do ensino médio, com os quais pesquisamos, sustentando que, em que pese desafios de várias ordens, existe espaço para um ensino de filosofia ligado à vida de jovens estudantes e na perspectiva de uma construção de uma ética do cuidado de si, em que se busca a livre transformação de si.

O ensino de filosofia, na educação brasileira, não navegou em águas pacíficas. Ao contrário, podemos considerar que seu percurso se deu em mar revolto e, por vezes, tenha naufragado ${ }^{2}$. Após inúmeras inserções e retiradas dos currículos das escolas nacionais, representado, conforme Alves (2002), pela

\footnotetext{
${ }^{1}$ Este trabalho retoma ideias da Dissertação de Mestrado intitulada "Da disciplina castrense à ética do cuidado de si: práticas e experiências do ensino de Filosofia no Colégio da Polícia Militar de Teixeira de Freitas, BA", aprovada em 2018, no Programa de Pós-graduação em Ensino na Educação Básica, Centro Universitário Norte do Espírito Santo (CEUNES), São Mateus, ES, Universidade Federal do Espírito Santo.

2 Apenas a título de exemplo, a Lei 5.692/71 teve o objetivo de organizar o Ensino Médio, na ditadura militar brasileira (1964-1985), de forma que, ao final do ciclo, profissionais fossem formados para ocupar as demandas de trabalho de baixo custo, acabou por retirar a filosofia e sociologia do currículo das escolas brasileiras.
} 
dialética ausência-presença, viveu um momento especial, devido à sua inclusão como componente curricular obrigatório no Ensino Médio, com a Lei 11684/2008 (BRASIL, 2008). Mesmo que não tenha sanado as dificuldades e desafios que envolvem seu ensino, a referida Lei trouxe entusiasmo e possibilidades concretas e efetivas capazes de seu ensino.

No entanto, mais uma vez retornou a tormenta que sempre insistiu em fazer o ensino de filosofia imergir. Com a nova Lei do Ensino Médio, Lei 13415/2017 (BRASIL, 2017), que reformulou a LDB, passa a constituir vagamente um campo de 'estudos', sem o status de disciplina, conforme se vê no parágrafo segundo da citada norma: "A Base Comum Curricular referente ao Ensino Médio incluirá obrigatoriamente estudos e práticas de Educação Física, Arte, Sociologia e Filosofia" (BRASIL, 2017), o que trouxe apreensão a educadores e profissionais comprometidos com essa área de conhecimentos.

Sobre o eventual fim da obrigatoriedade da filosofia, a partir da Lei citada, sinalizamos três possibilidades: inclusão apenas como tema transversal; uma inclusão apenas para as escolas que quiserem oferecê-la, e a desobrigação como disciplina tradicional. Ainda nos encontramos num momento em que os Estados, a quem incumbe a oferta do Ensino Médio, reorganizam seus currículos (SANTOS JR.; NEIRA, 2020).

A filosofia ficou durante muito tempo ausente da grade curricular das escolas de nosso país, causando o descrédito e desinteresse por esta disciplina, como afirma Gallo (2012, p. 159):

Como a retirada da filosofia dos currículos havia sido obra da reforma de cunho tecnicista da educação básica levado a cabo por aquele regime no final dos anos de 1960 e início da década de 1970, atribuía-se à exclusão da filosofia e de outras disciplinas de humanidades a falta de criticidade e o excesso de tecnicismo na formação dos jovens.

Percebemos que na educação brasileira ainda prevalece a perspectiva positivista de sobrevalorização das disciplinas das áreas de ciências naturais e matemáticas, ligada à preparação do jovem para o mercado de trabalho. E no que se refere à filosofia, com carga horária mínima (em geral, uma a duas aulas semanais), a maneira como os conteúdos são abordados em sala de aula se 
apresenta insuficiente, a nosso ver, para desenvolver no estudante uma atitude filosófica, prevalecendo conhecimentos prontos, mediante assimilação acrítica e mecânica, sem despertar o senso de investigação filosófica no estudante.

Nesse contexto problemático, nos encontramos como professor da disciplina numa instituição militar de educação nível médio: o Colégio da Policia Militar de Teixeira de Freitas, BA.

A criação de um colégio sob a direção da Polícia Militar no Estado da Bahia deu prosseguimento a uma tradição das forças militares no Brasil: criar e manter instituições militares de ensino com o objetivo de atender aos filhos dos próprios militares. Assim, em 1957 ocorreu a criação do Colégio Militar de Salvador, que estava vinculado diretamente ao Ministério da Guerra e às Forças Armadas, especialmente ao Exército. Do ano de sua criação até a época atual, muitas mudanças ocorreram: o corpo discente era, até o ano de 1993, constituído apenas de estudantes do sexo masculino. Contudo, a partir de 1994, discentes do sexo feminino passaram a ser também admitidas e, ainda, filhos de não militares, assim como se deu a criação de outros colégios em várias cidades da Bahia, como, por exemplo, o Colégio da Polícia Militar de Teixeira de Freitas, lócus dessa investigação.

O cotidiano dessas escolas assemelha-se aos quarteis: os alunos estão sempre fardados e precisam prestar continência a militares e professores, à bandeira, entoar o hino nacional, marchar, desfilar em eventos militares, se apresentar sempre de cabelos cortados, conforme o padrão militar. Em suma, os alunos vivenciam o ethos militar fundado na hierarquia e disciplina, bases do edifício castrense. As relações de autoridade e o respeito irrestrito à hierarquia e à disciplina são características militares aplicadas cotidianamente aos alunos dos Colégios Militares; por isso, desde cedo, a obediência tanto aos professores quanto aos superiores hierárquicos, militares ou alunos mais antigos ${ }^{3}$, são valores que implicam numa relação de subordinação, havendo a priori, portanto, pouco espaço para a liberdade de ser e pensar, valores que nos parecem afins à filosofia.

\footnotetext{
${ }^{3}$ No militarismo, antiguidade é posto. O militar veterano é chamado de mais antigo em relação aos novatos que são chamados de recrutas. $E$ os recrutas devem obediência ao mais antigo como o fato de prestar continência. Esse aspecto é dominante também nos colégios militares.
} 
É nessa realidade que encontramos a filosofia como disciplina no Ensino Médio. E uma das perguntas que conduziu este estudo assim se formulou: como se constroem as relações de ensino e aprendizagem em filosofia no Colégio da Polícia Militar de Teixeira de Freitas-BA? Como desafio, buscamos investigar tal problemática relacionando-a aos limites e possibilidades de se pensar e produzir o ensino de filosofia como ética do cuidado de si, logo, numa perspectiva de construção de si como seres livres e criativos.

Para a elaboração desse trabalho tomamos como referencial teórico o pensamento de Gallo (2000, 2008, 2012), Cerletti (2009), Kohan (2000) e, principalmente, Foucault $(2010,2014)$ e Larrosa $(1994,2002)$ para compreender e fundamentar a filosofia como ética do cuidado de si e estética da existência enquanto potência criadora de subjetividades livres e autônomas.

Dessa forma, este trabalho se inspirou livremente numa perspectiva de pesquisa cartográfica, pensando a pesquisa como acompanhamento de processos, sem um rígido quadro de hipóteses, mas marcados pelas forças e movimentos de nossa própria trajetória de descobertas e pelas interações decorrentes do contato com a escola, conforme Barros e Kastrup (2012). Sobretudo, como militar, consideramos que não estamos separados do objeto da pesquisa. Tomamos a cartografia como estar à espreita do que acontece e se inventa no campo como linhas de fuga criadoras, como viver experiência, no sentido de Larrosa (2002): procuramos nos deixar tocar pelo campo de pesquisa, sabedores que, para haver experiência, teríamos que estar abertos ao que nos afetava, para que algo pudesse nos acontecer, para que as coisas que vivemos e produzimos pudessem atravessar o pensamento e nos fazer pensar diferentemente do que pensávamos e constituir-nos como sujeitos autônomos, críticos e criativos.

Como estratégias de pesquisa, fizemos uso, também, de entrevistas abertas, observação participante na perspectiva delineada e diário de campo, durante o ano de 2017, na pesquisa de mestrado do Programa de PósGraduação em Ensino na Educação (PPGEEB), do Centro Universitário Norte do Espírito Santo- CEUNES/UFES. 
Nesse sentido, objetivamos neste texto discutir a filosofia e o seu ensino tendo como referencial teórico a ética do cuidado de si e estética da existência, colocando em relevância experiências filosóficas produzidas no cotidiano do Colégio da Polícia Militar de Teixeira de Freitas, BA.

\section{A filosofia e seu ensino}

No cenário educacional brasileiro, a filosofia enfrenta inúmeros desafios: políticas educacionais voltadas, primordialmente, para a formação de mão de obra para o mercado de trabalho, dando pouco valor a formação humanística ou filosófica; estudantes que não vêem utilidade nas disciplinas da área de ciências humanas, no caso em pauta, filosofia; professores que lidam, muitas vezes, com o ensino de forma dogmática, bem como docentes oriundos de outras áreas que ministram a disciplina de filosofia, entre outras. Além desses aspectos, consideramos, pelas pesquisas feitas, que são problemáticos os conteúdos e a forma como a disciplina é ensinada. Há uma priorização em temas filosóficos tradicionais como ética, lógica, entre outros, sem recurso à história da filosofia (textos de pensadores) como possibilidade de aprofundar conceitos trazidos em sala, bem como fazendo relação com as vidas dos (das) jovens que frequentam nossas escolas de ensino médio, como nos mostra Gallo (2012).

Nesse sentido, perguntamos: como trabalhar ética e lógica sem fazer menção às teorias de Aristóteles, por exemplo? Tal questão encontra respaldo em Tomazetti (2002, p. 72), que nos mostra que: "tratar filosoficamente determinados temas, articulando-os com questões filosóficas, pode ser muito difícil para um professor que não tome para si mesmo a filosofia como um exercício de reflexão constante" o que, a nosso ver, pressupõe um domínio razoável dos conceitos e da linguagem filosófica. Por outro lado, há também professores que se restringem à história da filosofia, fazendo desta o próprio conteúdo da disciplina. Sobre isso, Gallo e Kohan (2000, p. 194) já afirmavam que "não se pensa filosoficamente sem o recurso a uma história de mais de dois mil e quinhentos anos". No entanto, da mesma forma advertiam: 
A remissão à história da filosofia não pode significar um retorno ao mesmo: essa remissão deve ser essencialmente crítica e criativa [...] retomar um conceito é problematizá-lo, recriá-lo, transformá-lo de acordo com nossas necessidades, torná-lo outro (GALLO e KOHAN, 2000, p. 71).

A educação atual, com raras exceções, não exige que o estudante tome uma posição crítica diante dos problemas. Nesse contexto pouco propício ao filosofar, o ensino da filosofia muitas vezes se restringe a uma transmissão de conteúdos cujo objetivo é fazer com que o aluno acumule o máximo de informações possíveis no pouco tempo que lhe é reservado. Ao mesmo tempo, pensamos que se a educação, de forma geral, como dissemos, não se preocupa com a formação de senso crítico do alunado, aí se encontraria um lugar privilegiado da filosofia: juntamente com outras disciplinas correlatas, já que seu métier se faz com o confronto com textos e posições teóricas com reflexos na vida prática, tornar seu ensino vital, vibrante e, socraticamente, causador de movimentos de pensamento e confrontos de formas de vida, submetendo à análise a vida dos jovens e da sociedade.

Percebe-se, dessa maneira, um problema que inviabiliza a consolidação do processo formativo, que podemos considerar que se configura com a efetivação de uma mudança de atitude do aluno face ao mundo e a si mesmo, a partir de um pensamento crítico amparado pelas reflexões despertadas no encontro do pensamento do aluno com o pensamento dos filósofos. No entanto, em condições como as apontadas (professores sem formação adequada, ensino dogmático) isso é quase impossível de acontecer por se fundamentar, na maioria das vezes, num modo superficial de articulação entre as perspectivas dos filósofos apresentadas pelo professor acerca de um determinado tema e os conteúdos tidos como necessários ao ensino da filosofia. Assim, afirma Gallo (2008, p. 71):

Quando pensamos o exercício da filosofia na sala de aula, [...] a pergunta que se impõe é: estamos investindo em experiências de pensamento ou impondo uma recognição? Ou, em outras palavras: estamos ensinando a filosofia como 
atitude crítica e criativa ou estamos disseminando uma imagem dogmática do pensamento?

Como consequência, cria-se uma imagem distorcida do pensamento filosófico e do filosofar, transmitindo ao aluno não mais do que "fórmulas filosóficas" que passam a se constituir em modelos a serem aplicados na resolução de questões prontas (SAVIANI, 2013). Essa lógica do ensino faz da relação ensinar/aprender uma relação equivocada que não leva à construção do conhecimento crítico. Pois, nessa lógica, ensinar é transmitir as teorias e ideias dos filósofos e aprender é compreender adequadamente aquilo que foi explicado, fazendo uma correlação entre a explicação do professor e o que se encontra nas obras filosóficas para, posteriormente, o aluno repetir de forma clara aquilo que aprendeu. Isso é denominado por Rancière de razão explicadora, que se caracteriza pelo:

[...] princípio de uma regressão ao infinito: a reduplicação das razões não tem jamais razão de se deter. O que detém a regressão e concede ao sistema seu funcionamento é apenas o fato que o explicador seja o único juiz do ponto em que a explicação é ela mesma explicada. [...] O segredo do mestre é saber reconhecer a distância entre a matéria ensinada e o sujeito a instruir, também a distância, entre aprender e compreender (RANCIÈRE, 2002, p. 18).

Contudo, mesmo diante de um cenário aparentemente desolador, percebemos um solo fértil para a o cultivo de novas formas de lidar com a filosofia e seu ensino na educação brasileira. Na esteira do pensamento de M. Foucault e J. Larossa, que tomam a filosofia e seu ensino como cuidado si e estética da existência, vemos a possibilidade de transformação no se refere ao trato com a filosofia e seu ensino, objeto de nosso próximo tópico.

\subsection{0 ensino de filosofia na perspectiva da ética do cuidado de si}

Buscamos pensar a dimensão da filosofia e seu ensino como ética do cuidado de si e estética da existência a partir do pensamento de Foucault. Começamos por indagar: o que é filosofia? E para responder a essa pergunta nos apoiaremos no pensamento do argentino Cerletti. 
Cerletti (2009) afirma que o ensino de filosofia é, primeiramente, um problema filosófico e não pedagógico. O filósofo argentino, em seu livro $O$ Ensino de Filosofia como Problema Filosófico, sustenta que o pressuposto para se ensinar algo ou alguma coisa é saber o que é esse algo ou alguma coisa a ser ensinada. Em suas palavras, ainda mais:

Para levar adiante a tarefa de ensinar filosofia, uma série de decisões devem ser adotadas. Decisões que são, em primeiro lugar, filosóficas, para em seguida - e de maneira coerente com elas - elaborar os recursos mais convenientes para tornar possível e significativa aquela tarefa (CERLETTI, 2009, p. 9).

Daí se depreende um caminho metodológico para o seu ensino, pois é a definição adotada pelo professor acerca do que é filosofia que vai auxiliá-lo no processo de ensino e aprendizagem em filosofia. No entanto, essa pergunta comporta mais de uma resposta ou perspectiva. O que torna mais problemático, ainda, pensar e realizar seu ensino:

E, como sabemos, encontrar uma resposta unívoca para 'que é filosofia?' não somente não é possível, mas cada uma das eventuais respostas poderiam dar lugar a concepções diferentes da filosofia e do filosofar, o que influirá, por sua vez, sobre o sentido do ensinar ou transmitir filosofia (CERLETTI, 2009, p. 11).

Ora, a pergunta 'o que é filosofia?' nos leva a várias definições e perspectivas. É exatamente a escolha de uma ou mais perspectivas daquilo que o professor acredita ser a filosofia que influenciará toda sua maneira de ensinar. Dessa forma, concluímos que o ensino de filosofia, suas estratégias didáticometodológicas e o conteúdo que se pretende ensinar são determinados pela concepção que o professor toma para si.

Portanto, o professor de filosofia, quando ministra suas aulas amparado por determinada(s) estratégias didático/metodológicas já tem (ou deveria ter) ciência de que suas escolhas e estratégias são predeterminadas por uma ou várias perspectivas filosóficas, pois suas aulas são intimamente elaboradas e caracterizadas, além daquilo que se pretende ensinar (conteúdos), pela concepção de filosofia que adota o professor. Cerletti (2009, p.17) afirma que 
"haveria consequências didáticas diferentes se supuséssemos, por exemplo, que a filosofia é essencialmente o desdobramento de sua história, ou se a entendêssemos como desnaturalização do presente". Logo, não há uma didática geral para o seu ensino, pois cada concepção ou definição de filosofia ensejará métodos próprios para seu ensino.

Isso nos mostra, ainda, que não podemos tomar o ensino de filosofia como um problema meramente didático. É uma questão filosófica que requer problematização e possíveis respostas filosóficas para, a partir daí, de acordo com a perspectiva adotada pelo professor, se buscar a elaboração de um método de ensino. Nesse sentido, tomamos a filosofia aproximando-a da concepção foucaultiana da ética cuidado de si, estética da existência.

A filosofia tomada como cuidado de si pressupõe um exercício de si mesmo que, segundo Foucault (2010), versa sobre o que se pode pensar e o que se pode mudar no que se pensa, entendendo que educar não é a transmissão de um saber teórico ou uma habilidade, mas uma ação que implica ocupar-se consigo mesmo, implicando certo deslocamento do sujeito em direção a ele mesmo e em direção ao outro. O cuidado de si é atravessado pela existência do outro, o que acaba por constituir um sujeito ético.

Diante disso, as questões que surgem são as seguintes: o que selecionar como conteúdo para o ensino de filosofia na perspectiva do cuidado de si? Quais estratégias didático-metodológicas a serem utilizadas para o melhor desenvolvimento de aulas essa perspectiva?

Para responder a essa pergunta nos apoiaremos na teoria desenvolvida por Larrosa (1994), que nos parece de fundamental importância para o ensino/aprendizado em filosofia enquanto ética do cuidado de si, ao nos possibilitar uma metodologia apoiada nas ideias de Foucault para o ensino de filosofia baseado na noção da estética da existência.

Em seu texto Tecnologias do eu e educação, o filósofo espanhol busca nos estudos de Foucault ideias e procedimentos que permitam reconsiderar a noção de sujeito, apresentando, na forma de um modelo teórico, a constituição da experiência de si como o campo onde se produzem subjetividades. Esse modelo teórico será um instrumento importante para "mostrar a lógica geral dos 
dispositivos pedagógicos que constroem e medeiam a relação do sujeito consigo mesmo" (LARROSA, 1994, p. 36). Esses movimentos devem levar a outra ideia de formação:

Minha aposta seria pensar a formação sem ter uma ideia prescritiva de seu desenvolvimento nem um modelo normativo de sua realização. Algo assim como um devir plural e criativo, sem padrão e sem projeto, sem uma ideia prescritiva de seu itinerário e sem uma ideia normativa, autoritária e excludente de seu resultado [...] (LARROSA, 1994, p. 21).

É a partir daí que Larrosa (1994) desenvolve e apresenta os constituintes dos dispositivos pedagógicos que nos impelem a uma ação sobre nós mesmos: a estrutura da reflexão, o ver-se; a estrutura da linguagem, o expressar-se; a estrutura da memória, o narrar-se; a estrutura da moral, o julgar-se e a estrutura do poder, o dominar-se. Para o autor, essas cinco dimensões conformariam uma tecnologia do eu, ou uma técnica de $\mathrm{si}$, em funcionamento no que ele chamou de dispositivo pedagógico, que se estabelece sempre que se aprendem ou se modificam as relações que o sujeito estabelece consigo mesmo.

Seria possível proceder a um ensino de filosofia tomado como ética do cuidado de si e estética da existência numa instituição militar? Uma concepção de um modo de vida livre, autônomo, crítico e criativo no Colégio da Polícia Militar de Teixeira de Freitas (ou em outro qualquer)? Apesar de parecerem termos antitéticos, além de uma empreitada desafiante, a ela dedicaremos os próximos passos deste texto, com ousadia e modéstia, certos de que são passos iniciais e apenas esboçados.

\section{A educação militar e seus dispositivos: uma reflexão à luz de Foucault}

Conforme apontamos, a vida militar é dotada de especificidade e suas características exteriores não traduzem sua singularidade, a nosso ver, pouco estudada (CARVALHO, 2005). O texto mais conhecido, na área de ciências humanas, no qual por primeiro lugar tivemos contato com a origem do ethos militar na disciplina do corpo foi Vigia e Punir, de Foucault (2014). Por outro lado, buscamos, neste texto, ampliar nossas referências, visando expor o pensamento 
do filósofo francês naquilo que tem de potência para pensar uma educação como estética da existência, para além de uma disciplina heterônoma.

Nesta seção exporemos a história de nosso lócus de pesquisa, o Colégio Militar Anísio Teixeira, seu cotidiano marcado pela educação militar, disciplina e hierarquia. Visamos, assim, tomar como ponto de partida a realidade da escola militar e seu cotidiano para, então, na última parte deste trabalho, apontar outra possibilidade para o ensino de filosofia.

\subsection{Características do Colégio Militar Anísio Teixeira}

O Colégio da Polícia Militar Anísio Teixeira, no Município de Teixeira de Freitas, Bahia, objeto desse estudo, foi criado através do Decreto Estadual $n^{\circ}$ 10.087, de 12 de setembro de 2006, resultado da incorporação do antigo Colégio Estadual Anísio Teixeira, instalado no Bairro da Bela Vista, na mesma cidade. No texto Histórico CPM Teixeira de Freitas, lemos acerca do sonho da criação do Colégio:

Velho sonho de muito acalentado pela população teixeirense, um caminho de sucesso a partir de então começou a ser traçado por toda equipe formada para conduzir a escola. Diretores, professores e auxiliares e alunos passaram a ter como visão de futuro a busca incessante para tornar-se referência na prestação de serviço educacional público regular no Extremo Sul da Bahia, enfocando a valorização do ser humano na formação do cidadão, alicerçados nos pilares da ética, da responsabilidade, da disciplina, da transparência e do compromisso na preparação dos jovens para a vida. O CPM Anísio Teixeira oferta anualmente vagas para o $6^{\circ}$ ao $9^{\circ}$ anos do Ensino Fundamental e $1^{\text {a }}$ a $3^{\text {a }}$ séries do Ensino Médio (BAHIA, 2016).

Segundo os documentos oficiais (Plano Geral de Ensino e Projeto Político Pedagógico), os parâmetros educacionais foram estabelecidos pelos princípios dos direitos humanos, do civismo e patriotismo, bem como pelas tradições históricas da Instituição Policial Militar da Bahia, com o intuito de contribuir para o desenvolvimento e formação integral do educando e seu preparo para o exercício da cidadania: 
Sua organização faz-se necessária ao desenvolvimento de suas potencialidades, como elemento de auto realização e exercício constante da cidadania, despertando no discente o gosto pela carreira militar na corporação, através da instrução policial militar (BAHIA, 2016, p. 20-21).

O CPM de Teixeira de Freitas é responsável atualmente pela educação de 567 estudantes nos dois turnos de funcionamento (matutino e vespertino). Conta com 23 docentes civis e 09 docentes militares. Os primeiros são lotados na Secretaria de Educação do Estado da Bahia, sendo que 19 dos 23 docentes são efetivos e 04 são estagiários do projeto $\mathrm{IEL}^{4}$, enquanto os últimos são Policiais Militares (Oficiais e Praças), que ministram aulas em regime especial de ensino.

A seguir, adentraremos numa descrição do cotidiano do Colégio, suas regras tácitas e ethos de formação do aluno, visando nos aproximar de nosso objetivo principal, qual seja, apontar a possibilidade de um ensino de filosofia que se relacione com o cuidado de si e uma estética da existência.

\subsection{0 cotidiano do Colégio Militar}

O colégio abre seus portões às $06 \mathrm{~h} 45 \mathrm{~min}$, quando o contingente de 567 alunos $^{5}$ é orientado a adentrar o recinto escolar de forma ordeira e disciplinada: caminham em direção à sala de aula, deixam suas mochilas em suas carteiras e seguem para a quadra poliesportiva, onde acontece a chamada formatura: todos são posicionados em fila indiana, perfazendo um total de dez filas próximas umas das outras.

A realização da formatura é feita através da voz de comando militar: "atenção, sentido, cobrir, descansar". Em seguida é entoado o hino nacional, o hino da Bahia e o hino do CPM. Após esse momento acontece a revista. Todos

\footnotetext{
${ }^{4} \mathrm{O}$ Instituto Euvaldo Lodi (IEL) desenvolve um trabalho com objetivo de preparar as empresas brasileiras para um ambiente de alta competitividade, oferecendo soluções em gestão corporativa, educação empresarial e desenvolvimento de carreiras. Todos os anos o programa IEL de Estágio aproxima estudantes universitários e de cursos técnicos do mercado de trabalho através de estágios remunerados.

${ }^{5}$ O CPM de Teixeira dispõe de 567 vagas anuais. Segundo o Coordenador Pedagógico, após as reformas e ampliações na estrutura do prédio, a expectativa é de que haja um aumento significativo no número de vagas.
} 
os alunos são submetidos a um criterioso exame com o intuito de verificar se o fardamento está completo e limpo, se os cabelos estão de acordo o regulamento e se faltou algum discente. Depois da revista são anunciados avisos. Importante destacar: todos os dias acontece da mesma maneira.

Após a formatura todos vão apara sala de aula, na qual existe um líder responsável por apresentar a turma ao professor e passar todas as informações necessárias, tais como: se o colega está de atestado ou se foi ao banheiro etc. Este líder é chamado de xerife da turma, ele é a segunda autoridade na sala de aula, tendo o dever de fiscalizar a todos e manter a ordem em sala. O xerifado tem duração de uma semana.

Quando o professor entra em sala de aula o xerife já está de pé e, em posição de sentido, brada em voz alta: "atenção, sentido". Nesse momento toda a sala fica de pé e em posição de sentido. A seguir, o xerife continua: "presença em sala de aula do $1^{\circ}$ Tenente PM Immanuel Kant, professor da disciplina Instrução Militar". Assim é apresentado o professor que retribuirá a apresentação com uma continência e em seguida determina a todos se assentarem em seus lugares para que tenha início a aula.

O xerife é responsável pela fiscalização do ambiente de sala de aula. Já para a fiscalização e manutenção da ordem de toda escola, há a figura do Aluno de Dia. O Aluno de Dia é superior ao xerife e comanda a todos. O aluno de Dia é responsável por todo o Colégio durante o dia. Como têm que seguir a hierarquia, só podem ser Alunos de dia os alunos do ensino médio, pois são considerados "mais antigos". E, ao final de cada dia, o Aluno de Dia entrega à secretaria o livro de parte com o relato pormenorizado de tudo que aconteceu durante o dia.

Há também as Paradas. As paradas são reuniões semelhantes às formaturas, mas que só acontecem semanalmente. As paradas têm duração de cinquenta minutos, em que são lidas as punições e elogios. Seguindo a mesma ritualística, os alunos se colocam de pé em frente ao superior e escutam a leitura dos Boletins Interno-Ostensivos - BIOs. Os alunos que, de alguma forma ou outra, tenham desrespeitado as regras, são punidos. E aqueles que se destacam ganham os elogios. 
Todo Colégio militar tem suas atividades pautadas na doutrina ideológica do Exército Brasileiro: a disciplina e hierarquia. O corpo docente de um Colégio Militar, como vimos, é formado por professores civis e militares. As relações de poder e o respeito irrestrito à hierarquia são características militares aplicadas cotidianamente aos alunos dos Colégios Militares; por isso, desde cedo a obediência tanto aos professores quanto aos superiores hierárquicos, militares ou alunos mais antigos, são valores que implicam numa relação de subordinação, de fazer prevalecer a vontade do superior, que detém o poder sobre o subordinado, não havendo, portanto, uma relação própria de igualdade, haja vista que no meio militar a autoridade deriva da hierarquia, antiguidade e/ou merecimento .

Foucault considera que as relações humanas são relações de poder, as relações de poder e saber estão mutuamente implicadas: enunciados e visibilidades, textos, instituições e práticas sociais. Nas já clássicas obras Vigiar e Punir e Microfísica do Poder lemos que o poder se exerce na sociedade não apenas através do Estado e seus órgãos repressivos ou suas autoridades constituídas, mas que o mesmo se manifesta de diversas maneiras e com sentidos variados que, por vezes, passa despercebido devido à forma sutil com que se apresenta. Todavia, no Colégio da Polícia militar a relação de poder se manifesta não com a sutileza expressada por Foucault. Apresenta-se de forma visível, explícita, com o ritual descrito pelo pensador francês em Vigiar e punir ao descrever a formação das disciplinas.

Conforme mostra Foucault (2014), no início do século XVII, Walhausen, em sua obra L'Art militaire pour l'infanterie, expõe a "correta disciplina" como uma arte do "bom adestramento". O filósofo francês ressalta que "o poder disciplinar é, com efeito, um poder que, em vez de se apropriar e se retirar, tem como função maior 'adestrar'; ou sem dúvida adestrar para retirar e se apropriar ainda mais e melhor" (FOUCAULT, 2014, p.167). Com efeito, os manuais de instrução militar tratam os períodos do ano de instrução como períodos de "adestramento". A utilização da indumentária no meio militar serve para padronizar a aparência e despersonalizar o indivíduo que, a partir sua “incorporação" na Instituição, recebe um número que passará a ser sua nova 
"identidade". Posteriormente, o posto ou graduação virão sempre precedendo seu "nome de guerra".

No âmbito do Colégio Militar, existe o Regulamento Disciplinar do Colégio da Polícia Militar (RDCPM) que define o padrão comportamental de seus alunos. Nele estão elencados os princípios gerais da disciplina, passando pela especificação das transgressões, critério de julgamento e de classificação, chegando às punições correspondentes, gradação, forma de execução e normas para aplicação. Trata-se de um regulamento cujas normas são extremamente claras, não deixando pairar no aluno qualquer dúvida quanto ao correto procedimento, posto que estão definidas cuidadosamente as condutas transgressionais em 99 incisos, com classificação que varia de leve a eliminatória, evidenciando, outrossim, as punições a que estão sujeitos seus infratores, variando de advertência à exclusão disciplinar.

Segundo Foucault, (2014, p. 168) a "disciplina fabrica indivíduos", é a técnica específica de um poder que toma os indivíduos ao mesmo tempo como objetos e como instrumentos de seus exercícios:

O exercício da disciplina supõe um dispositivo que obrigue pelo jogo do olhar; um aparelho onde as técnicas que permitem ver induzam a efeitos de poder, e onde, em troca, os meios de coerção tornem claramente visíveis aqueles sobre quem se aplicam (FOUCAULT, 2014, p. 169).

O pensador faz alusão à "vigilância hierárquica", quando afirma que "o olhar disciplinar teve, de fato, necessidade de escala" (FOUCAULT, 2014, p. 171). O trabalho de Foucault que deu origem à sua obra Vigiar e Punir é um estudo das diversas formas de violência nas prisões, mas a essência de sua análise se enquadra nas diversas instituições que fazem uso de sistemas normativos da vigilância hierárquica, dos aspectos punitivos em geral, nas ações controladoras e disciplinadoras, como manicômios, presídios, escolas, quartéis, colégios militares etc.

Essa "vigilância hierárquica" e esse "olhar disciplinar", aos quais se refere Foucault, no âmbito dos Colégios Militares são aspectos trabalhados cotidianamente e denominados de "disciplina consciente", conforme seu regulamento mostra em vários artigos: Art. $6^{\circ}$. I) Obediência à hierarquia e 
disciplina". Art. $8^{\circ}$. São manifestações essenciais dos valores institucionais dos alunos: II - o respeito e o devotamento ao Colégio da Polícia Militar (CPM) e às suas tradições; III - o civismo; IV - a fé na elevada missão da Polícia Militar. Além desses, podemos citar o Art. 10. Deontologia estudantil: III - cumprir e fazer cumprir as leis, os regulamentos, as instruções e as ordens das autoridades competentes, à exceção das manifestações ilegais; $X$ - conduzir-se de modo que não sejam prejudicados os princípios da disciplina, hierarquia, respeito e decoro apregoados por este Estabelecimento de Ensino; XI - zelar pelo bom conceito da Polícia Militar e do Colégio da Polícia Militar (BAHIA, 1997, p. 6-7).

A partir das conceituações de Foucault, podemos perceber como a disciplina, ao lado da hierarquia, regula a vida dos discentes. O ensino nos Colégios Militares é um instrumento preparatório que visa à formação dos alunos e, também, à carreira militar. Portanto, a aplicação do ethos militar no Sistema dos Colégios Militares é uma realidade que se estende, também, aos alunos que não irão seguir a carreira militar.

Considerando o aparato disciplinar citado, como contraponto à disciplina, ao "vigiar e ao punir", nos permitimos dar um salto para além da realidade dada e nos fazer, como desafio teórico e prático, consoante a parte da obra de Foucault dedicada ao sujeito ético, a seguinte questão: mesmo com todo este aparato disciplinador, há espaço para a criação, singularidade, para a vida acontecer de outras formas nessa escola? Há espaço e possibilidade do ensino de filosofia acontecer como cuidado de si, como uma estética da existência? $\mathrm{Na}$ última seção deste texto, narramos o percurso que busca responder a nosso objetivo, percurso que nos inseriu na escola em conversas com alunos e professores, apontando outras possibilidades de uma vivência da disciplina, no espírito de uma construção subjetiva em que os jovens possam se reconhecer como sujeitos livres, responsáveis e, por que não dizer, felizes?

\section{Experiências do ensino de Filosofia no Ensino Médio de um Colégio Militar: para além da disciplina, o cuidado de si}

A questão que nos colocamos assim se exprime: existe, nesse contexto escolar, a possibilidade de fazer experiências de um ensino significativo de 
filosofia como cuidado de si? Como experimentar uma questão filosófica, para além do modo 'disciplinar'? Sabemos que tais questões abrem diversas perspectivas. Nesse sentido, recorremos a Larrosa (2002) como suporte necessário ao desenvolvimento das aulas de filosofia como estética da existência.

Reiteramos que as experiências narradas foram 'capturadas' numa pesquisa de campo qualitativa, na qual apostamos num modo de fazer pesquisa considerando os processos de produção de dados, por inspiração em princípios da cartografia deleuziana, que visa acompanhar processos, conforme Barros e Kastrup (2012). Salientamos, também, que descreveremos uma pequena parte dos acontecimentos pelo motivo de não haver espaço nesse artigo para a descrição de todas as atividades realizadas durante a pesquisa. E que ainda demandariam outras análises.

Por seis meses nos lançamos numa aventura cartográfica para apreender a realidade do Colégio da Polícia Militar e, em especial, a dinâmica do ensino de filosofia numa turma ("B") do $2^{\circ}$ ano do Ensino Médio, período matutino, constituindo-se num fértil espaço no qual observamos, interagimos, buscando entender as formas como o ensino de filosofia se delineava e como era construído naquele contexto. A turma citada era composta por 30 alunos, sendo 17 do sexo masculino e 13 do sexo feminino. O (ou a) docente tinha formação superior em Pedagogia e lecionava a disciplina de filosofia.

No quinto e sexto dia de observação, realizamos a entrevista com o professor da disciplina. Como havíamos feito desde início, não levamos nada pronto, nada programado, apenas um roteiro aberto. Apenas deixamos que as coisas acontecessem de forma espontânea, e em meio a um rico diálogo, um "bate papo" frutífero, pudemos colher dados importantes para esta pesquisa.

Indagamos se havia dificuldades em ensinar filosofia, considerando sua formação em pedagogia e que lecionava outra disciplina. Suas palavras demonstram que não é simples ser professor sem a formação específica, confirmando o que já discutimos com Cerletti (2009), no sentido de que o ensino de filosofia é (principalmente) um problema filosófico e não (meramente) didático ou metodológico: 
Além de filosofia eu ensino sociologia e atualidades. Confesso que na disciplina de atualidade as aulas fluem melhor, conseguimos discutir coisas mais próximas da realidade dos alunos. E encontrei dificuldade em filosofia e bem menos em sociologia. A maior parte dos alunos não gosta de filosofia, não se esforçam muito e percebo que é só mais uma disciplina para eles decorarem para a prova (DIÁRIO DE CAMPO, DOCENTE DE FILOSOFIA).

E foi pensando em discutir a temática filosófica dos conteúdos ministrados no CPM que perguntamos: em relação aos conteúdos, quais conteúdos são trabalhados, quais livros, quais filósofos e autores? Qual o critério utilizado para seleção dos temas?

A escola indica o livro Fundamentos da Filosofia, de Gilberto Cotrim. Esse livro já traz tudo bem explicado, bem esmiuçado. É um livro que trata de assuntos como: a busca pelo conhecimento, a vida e a morte, natureza humana, ideologia e etc. No $2^{\circ}$ ano $B$ os alunos prestam mais atenção. Mas no $3^{\circ}$ eles dispersam muito, não prestam atenção. No $2^{\circ}$ também, só que bem menos. Eles ainda debatem um pouco. Mas penso que não é só nas aulas de filosofia, isso é geral em todas as disciplinas. Então, eu tento trabalhar de forma prazerosa, tentando esmiuçar ainda mais o assunto. Eu trabalho o livro indicado pelo colégio, porque é regra, o livro tem que ser trabalhado. E utilizo também o livro Introdução à Filosofia, de Maria Lúcia de Arruda Aranha. Já utilizei também de Marilena Chauí, mas pouca coisa (DIÁRIO DE CAMPO, DOCENTE DE FILOSOFIA).

O que depreendemos da fala do (a) docente é que o CPM de fato é um colégio rígido, conforme já descrevemos, justamente pelo fato de ser militarizado, e que tal ethos castrense parece atingir tanto os alunos quantos os professores, e também influenciar, e às vezes de forma negativa, o fazer do professor. Confirma-se, pelo depoimento, que os livros são escolhidos pela Direção, as provas são analisadas pela Direção antes de serem aplicadas, indicando ausência de autonomia por parte dos educadores. Acresce-se a tal prática a falta de formação específica do docente para a disciplina, apontando desafios adicionais a um ensino significativo da disciplina filosofia.

Após o diálogo com o (a) professor (a) conversarmos com os alunos. Eles estavam mais à vontade com nossa presença em sala de aula e, 
espontaneamente, fomos aos poucos estabelecendo interessantes diálogos. A cada intervalo e a cada dia nos conhecíamos através de nossas conversas. Entre outros tópicos, indagamos pela motivação de estudar naquela instituição; destacamos a fala do aluno 01 :

Meu pai sempre quis me matricular aqui porque é um dos melhores colégios de Teixeira. Muitos dos meus amigos que estudaram aqui, hoje estão cursando o ensino superior em universidades públicas ou ganharam bolsas nas particulares. O ensino aqui é muito bom (DIÁRIO DE CAMPO, ALUNO 01).

Acerca do mesmo assunto, os alunos 02 e 03 se pronunciaram:

Realmente o ensino aqui é nota dez. Minha irmã esta na Universidade Federal do Sul da Bahia - UFSB. Ela estudou aqui (DIÁRIO DE CAMPO, ALUNO 02).

Realmente o ensino é muito bom. Mas para mim que não quero seguir a carreira militar, acho desnecessárias as matérias de Direito. Além de eu não entender nada não servirá para mim, nem no vestibular cai. Deveria dar mais aulas de português e redação no lugar de Direito (DIÁRIO DE CAMPO, ALUNA 03).

Questionamos os alunos a respeito das aulas de filosofia, o que pensavam e como se relacionavam com a disciplina, se fazia sentido em suas vidas:

(...) Vamos ser sinceros, filosofia para quê? Ficar debatendo um monte de coisa que nem faz sentido, a realidade totalmente diferente. $E$ ainda ter que saber quem foi Platão e os livros que ele escreveu. Sinceramente eu não quero ser professor e jamais ser professor de filosofia. Eu acho bem melhor que no lugar de filosofia tivesse mais aula de história, pois além de ser menos chata cai no vestibular (DIÁRIO DE CAMPO, ALUNA 04).

À medida que nosso bate papo se desenvolvia percebemos que a maioria dos alunos compartilhava da mesma visão e sentimento: acreditam que o CPM os ajudará a cursar o nível superior e/ou levá-los a carreira militar sem, entretanto, ter a mesma relação com o ensino de filosofia, percebida como desinteressante e sem ligação com suas vidas.

Os alunos parecem que tentam se adaptar, visto que muitos estão no CPM porque pensam que é uma escola que lhe darão conhecimento necessário 
para passar nos vestibulares e Enem. A nosso ver, conforme suas falas, se acostumam com a rigidez e alguns até acabam mesmo internalizando o ethos militar, muitos deles passando a gostar; outros, no entanto, vêem a escola militar como passagem para a universidade.

Quanto ao ensino de filosofia percebemos que é um tanto problemático: o (a) docente não é formado (a) na área, é pedagogo (a). E, por mais esforço que realize para ensinar a disciplina, é perceptível que a ausência da formação o (a) limita em seu fazer pedagógico-filosófico, além do rígido controle quanto ao livro a ser ensinado. Tais elementos, a nosso ver, explicam que as aulas de filosofia não despertem tanto interesse junto aos alunos, acarretando que muitos cheguem a desprezar a disciplina.

Mas, diante dessa realidade, nos desafiamos a experimentar outra possibilidade de ensina filosofia no Colégio Militar: como um cenário propício à filosofia como ética do cuidado de si. E foi com esse pensamento que nos propusemos, juntamente com o (a) docente responsável, a realizar atividades relacionadas a outra prática do fazer filosófico, visando despertar autonomia, criticidade e liberdade. Buscamos colocar em prática, através da atividade "Café Filosófico", a teoria do cuidado de si e estética da existência. A seguir, narramos, ainda que esquematicamente, tal iniciativa.

\subsection{Interrogar-se e narra-se para cuidar de si num ambiente} militarizado

Através de pesquisa bibliográfica, utilizando o critério de planejar uma ação que envolvesse docente, pesquisador e alunos, com o objetivo de mostrar que a filosofia era, no seu nascimento na Grécia, diálogo entre iguais, sem hierarquia, em busca do sentido da vida e da construção de vida pessoal, encontramo-nos com Marc Sautet (2013) que, na obra “Um café para Sócrates”, nos apresenta a filosofia como discussão vital, seja sobre a crise do mundo atual, seja sobre as crises existenciais como as que acometem os jovens. Com as devidas autorizações, após reuniões com o (a) docente e coordenadores, fomos a campo (ou à sala de aula). 
Em planejamento com o (a) docente da disciplina, definimos data, objetivos, conforme andamento do conteúdo e com o horário disponível do pesquisador, tivemos um primeiro encontro com a turma, visando expor os objetivos da pesquisa, apresentar a metodologia e solicitar as autorizações devidas (cada discente apresentou autorização para a atividade, na qual constou: objetivo da atividade, tempo previsto, autorização para participação, enfatizando que não revelaríamos os nomes e imagens dos (as) participantes).

Numa manhã de agosto de 2017 aconteceu nosso Café Filosófico. A sala de aula se transformou num cenário diferente dos dias normais: as carteiras não estavam em filas e sim dispostas circularmente, a ornamentação deu um "ar" diferente ao ambiente, não parecia que estávamos numa escola militar. Os alunos demonstravam estar contentes com a novidade. Contudo, não podendo fugir à rotina da instituição, entraram em forma, passaram pela revista, cantaram os hinos e se dirigiram à sala da aula. Ao chegarem ao espaço designado para a atividade, foram recepcionados com música, receberam caneta e agenda, bem como uma numeração contendo dados correspondentes ao seu grupo.

Conforme expusemos anteriormente, trouxemos, para nossa perspectiva de um ensino de filosofia como ethos do cuidado de si, 03 (três) dispositivos pedagógicos de subjetivação: o ver-se, o expressar-se e o narrar-se. Larrosa (1994) propõe que essas atividades sejam realizadas de forma que os alunos produzam seus textos, seus discursos a partir da experiência de si mesmos, sem que haja algo anterior, como manuais ou explicados do (a) professor (a). Então, iniciamos a dinâmica do espelho.

A turma foi dividida em cinco grupos, aos quais foram entregues seis caixas de diferentes cores com um espelho em seu interior, de modo que ao abrila cada integrante visse seu próprio reflexo. Após abrir a caixa e ver o seu conteúdo, cada grupo foi convidado a pensar acerca do que viu, considerando as seguintes questões: "Quem sou eu? Quem determina meu agir? Sou livre? O que é liberdade? O que gostaria de mudar em mim? Como gostaria que os outros me vissem? O que quero ser? Sou responsável? Se pudesse ser outra pessoa quem gostaria de ser?" Cada grupo teve seis minutos para se expressar aos demais, além do tempo para um diálogo posterior. 
Dentre várias respostas dos (as) discentes, destacamos algumas que nos pareceram mais representativas:

Aluno 1: Ao me ver no espelho para daí dizer coisas sobre mim é algo, como por exemplo, quem eu sou, me faz achar que sou um adolescente que acredita na educação, na liberdade, mas que a liberdade não é total. A liberdade é parcial. Ninguém é cem por cento livre. Gostaria de ser um pouco mais alto, mas gosto de ser quem sou e sei bem o que quero ser: um médico!

Aluno 2: Também entendo dessa forma, ninguém é totalmente livre. Nós não podemos fazer tudo que queremos. Eu quero ter minha independência, ter minha casa, não depender de ninguém a não ser de mim mesmo. Mas, mesmo sendo independente, não podemos fazer tudo. Pois, como dizem, meu direito termina onde começa o do outro.

Aluno 3: Quando me vi no espelho, eu vi a imagem de um ser humano que pode ser tudo o que sonhar. Que pode se dar bem na vida, mas também que pode se dar mal. Tudo vai depender das minhas escolhas. Eu quero muito ser advogada e estou batalhando para isso, pois quando terminar o Ensino Médio vou cursar Direito. Eu escolhi que quero ser advogada, não foram meus pais. Então, sou livre para fazer minhas escolhas. Porém, não tenho tanta liberdade para escolher todas as coisas que quero, por exemplo, não posso decidir morar só, pois não tenho condições e nem meus pais deixariam. $E$, mesmo tendo condições de me manter, eles não deixariam. Então realmente a liberdade é algo limitado.

Aluno 4: Eu sou um adolescente em busca de realização profissional e pessoal. Sou um filho que dependo dos pais. Mas sei que para realizar meus sonhos e objetivos eu tenho que correr atrás... O que meus pais podem me dar eles já estão me dando, agora eu tenho que estudar, me dedicar para que eu consiga realizar tudo que quero.

Aluno 5: Tudo na vida tem regras, o excesso de regras impede a nossa liberdade. Quem eu sou? Eu sou uma pessoa que tem que se encaixar, que tem que respeitar as regras para não ser punida. A gente não pode ser a gente mesma, ou tem que ser pela metade, porque não podemos fazer tudo que queremos, não podemos dizer tudo que queremos dizer, e é tão difícil ser quem 
realmente queremos ser. Eu não queria morar em Teixeira, queria ficar em Itabuna. Não queria estudar aqui, queria ficar no meu colégio Sistema. Mas quem decide tudo são meus pais. Quem eu sou? Sou aquela que faz tudo (ou quase tudo) de acordo com a vontade de meus pais. Isso é não é legal! Mas tenho que fazer senão as coisas ficam feias para mim. Mas ficarei maior de idade, e as coisas vão mudar, tenho fé!

Dos trechos selecionados, pudemos perceber as possibilidades que podem ter uma aula de filosofia em que os alunos podem fazer uso do lógos, do discurso para se expressarem, reafirmando o que ressoa das propostas de Gallo, Kohan e outros autores, como Rancière: em filosofia, não existe lugar para doação de sentido ao outro, para explicação da relação que cada um deve construir com sua vida. Tal constatação veio ao encontro das análises feitas em nossa pesquisa bibliográfica: assumindo a igualdade das inteligências, a filosofia se torna uma busca comum de sentido para a vida, mediada pela relação de amizade com o saber, em que a filosofia deixa de ser conteúdo doutrinário sobre pensadores e se torna pensamento ativo sobre a vida, seus caminhos, descaminhos, possibilidades e sonhos. Sentimo-nos como Sócrates na Atenas de seu tempo, dialogando entre jovens e suas aspirações!...

Nesse sentido, mesmo considerando as limitações dessa intervenção, percebemos que, conforme Larrosa (1994, p. 46), o discurso pedagógico deve ser interrogativo, de modo a que os (as) discentes produzam seus "próprios textos de identidade". Por isso, aquela atividade não teve início com uma explicação textual ou verbal. O intuito foi proporcionar uma atmosfera, uma circunstância, um ambiente que propiciasse a exposição de um discurso proferido pelo educando a partir da experiência de si mesmo, pois tínhamos a convicção de que o discurso dos (as) estudantes se constrói de forma a projetarse a si mesmos e aos outros, construindo um discurso ao mesmo tempo em que, segundo Foucault (2004), o discurso os constroem também, dando-lhes um significado legítimo. O que os discentes aprendem é uma gramática para a auto interpretação e para a interrogação pessoal e do outro, levando-os a refletir acerca de sua condição de ser humano, de sua condição de sujeito. Em geral, essa é "uma gramática para a interrogação pessoal do eu. Aprendendo os 
princípios subjacentes e as regras dessa gramática, constrói-se uma experiência de si” (LARROSA, 1994, p. 46).

Após essa dinâmica filosófica, os (as) alunos (as) foram convidados (a) a analisar, confrontar e refletir suas experiências com os textos de filósofos da tradição, que já estavam presentes no livro didático adotado pela Instituição (conforme citado, trata-se do livro de Cotrim, 2000).

A partir do ver-se e das questões propostas, os (as) discentes puderam interrogar-se a si mesmos, objetivando fazer nascer a experiência de si, num jogo de experimentação de problemas que afetassem seus pensamentos, levando-os a problematizar e a refletir não apenas sobre tais problemas, mas antes de tudo, acerca do seu próprio eu e acerca do outro com o qual se relacionam, problematizando a sua condição no mundo. Assim, objetivamos que os (as) discentes tivessem a oportunidade de descobrir o "significado específico da singularidade do eu e da compreensão mútua, no sentido de significado específico para coisas como autoconhecimento e auto avaliação, sinceridade, comunicação e compreensão (LARROSA, 1994, p. 46), mediante a filosofia. Para tal objetivo, foi oportunizado conversarem entre si, se questionarem, estabelecendo um diálogo que nos pareceu profícuo e autêntico.

Nessa fase da dinâmica, três elementos dos dispositivos pedagógicos propostos estiveram em jogo: o ver-se, o expressar-se e o narrar-se. Deste modo, Larrosa (1994) distingue inicialmente a estrutura óptica do ver-se, que constitui um conjunto de tecnologias que organizam aquilo que um sujeito consegue ver de si mesmo, enxergar em si mesmo graças às técnicas de reflexão que fazem da atividade do conhecer-se algo semelhante ao posicionamento de um espelho, de uma lâmina, de uma superfície de transparência ideal na qual o sujeito possa ver e reconhecer sua própria imagem.

Em seguida, Larrosa (1994) distingue a estrutura discursiva do expressarse e seu agenciamento temporal sob a forma do narrar-se. Trata-se, aqui, do modo como a linguagem é representada nesse dispositivo: como um mecanismo de expressão, onde o sujeito expõe, exprime, por meio de palavras, aquilo que ele supostamente já é. Mas, também, como uma forma de prestar contas sobre si mesmo mediante toda uma estruturação temporal dessa expressão. "Seria 
possível, pois, considerar a estrutura geral do expressar-se como a dobradura reflexiva sobre si próprio, dos procedimentos discursivos que constituem os dispositivos de construção e mediação da experiência de si" (LARROSA, 1994, p. 65). Isto se refere à subjetivação que ocorre mediante uma construção narrativa em que o sujeito é ao mesmo tempo o autor, o personagem principal e o relator de uma história. E um de cada vez expuseram aos demais colegas como eles se viam a si mesmos, pois “(...) 'ver a si próprio' é uma das formas privilegiadas de nossa compreensão do autoconhecimento" (LARROSA, 1994, p. 56).

Para Foucault (2010), o exame que realizamos acerca de nós mesmos é algo que requer uma atenção no olhar. Olhar para nós mesmos no intuito de nos compreender e, dessa forma, compreender a relação estabelecida entre o sujeito consigo mesmo e com os outros, como uma tomada de consciência que nos leva a enxergar quem somos nos preparando para um viver e agir de forma autônoma, livre e consciente. Dessa forma, nossa atividade visou apresentar a filosofia como um caminho possível desse empreendimento pessoal de pensar sobre si mesmo

\section{Conclusões (ou: começar de novo)}

$\mathrm{Na}$ escola pesquisada confirmamos o que apareceu em nossa pesquisa bibliográfica: dificuldades e desafios pelos quais passam professores e alunos apresentados à filosofia na escola, como ausência de formação específica de docentes, poucas aulas disponíveis, entre outras. Das observações e dados produzidos na escola militar, foi possível perceber entraves que dificultam o ensino de filosofia, levando a uma realidade preocupante, com um ensino até certo ponto controlado, cabendo pouco espaço de autonomia ao professor; exemplo disso é a constatação de que o material didático, ou seja, os livros da disciplina trabalhados em sala de aula são rigorosamente escolhidos pela direção do colégio; o professor que leciona é formado em outra área, pedagogia. $E$ as aulas acontecem de maneira que não levam o aluno a pensar, a refletir, considerando que a explicação dos problemas propostos é dada tanto pelo livro quanto pelo próprio professor, o que nos remete a um embrutecimento da 
relação humana e pedagógica, nos termos discutidos por Rancière (2002), encontrando respaldo nos discursos dos alunos participantes, ao deixarem claro que, no formato em que as aulas meramente expõem nomes, obras e datas, não têm sentido para eles.

Contudo, o colégio militar apresenta-se como um espaço potencialmente rico para uma nova experiência com o ensino de filosofia voltado para a afirmação da vida numa perspectiva autônoma, responsável e de liberdade. A filosofia como cuidado de si ou estética da existência proposta por Foucault, segundo indicações metodológicas de Larrosa, ensaiou levar ao ambiente militar uma nova forma de se relacionar com essa disciplina tão antiga e com condições de ser tão nova a cada vez que é ativada.

Em que pese o pouco tempo, bem como a necessidade de passar por outras experiências, buscamos engendrar transformações no modo de pensar, de agir e de se construir através de uma proposta com uma orientação filosófica, segundo Cerletti, visando a construção de si mesmo como sujeito em relação com outros, aberto ao diálogo e a outras possibilidades de se constituir (estética de si).

O Café Filosófico realizado no CPM foi uma prova suficientemente positiva de que podemos fazer um ensino de filosofia diferenciado, ensaiando outra forma de ensinar, para além do que estabelecem as diretrizes do Colégio, que se esmera em 'cumprir' o currículo prescrito nos documentos oficiais, sobretudo porque muitos conteúdos são exigidos nos exames oficiais, como o exame nacional do ensino médio (ENEM).

Por outro lado, em nossa proposta de pesquisa, o professor não ficou restrito ao livro didático que é exigido pela escola: o Café Filosófico nos mostrou que discentes apreciam discutir as questões e os problemas filosóficos da tradição naquilo que têm relação com suas vidas e expectativas, pois o que foi levado em consideração foi a vida de cada aluno, seu cotidiano, suas experiências e anseios. A partir disso, o professor pôde convidá-los a confrontar suas ideias com as ideias dos filósofos e abrir espaço para que, de forma dialógica e discursiva, cada discente chegasse a conclusões de forma autônoma e crítica. 
Portanto, nosso intuito não foi mudar o ethos vivenciado no CPM. Mas, abalar, de certa forma algumas estruturas que, a nosso ver, impossibilitam o desenvolvimento do ensino e aprendizagem em filosofia no CPM. E mais, apresentar uma nova forma de ensinar e aprender filosofia.

\section{Referências}

ALVES, D. J. A Filosofia no Ensino Médio: ambiguidades e contradições na LDB. Campinas, SP: Autores Associados, 2002.

BAHIA. 150 anos da Polícia Militar da Bahia. Estado da Bahia, 1975. BAHIA, Governo do Estado da. Manual Básico do Aluno-Oficial. Estado da Bahia, 1988.

. Manual do Aluno-CFAP. Estado da Bahia, 1997. [mimeo].

. Resumo histórico; 1825-1971. Estado da Bahia, 1972. [mimeo].

. COLÉGIO MILITAR DE SALVADOR. Histórico. Salvador, 2011. Disponível em: http://www.cms.ensino.eb.br/ Acesso em: 13.set 2016.

. COLÉGIO DA POLÍCIA MILITAR ANÍSIO TEIXEIRA. Plano Geral de Ensino. Teixeira de Freitas, 2016. [mimeo].

BARROS, L. P.; KASTRUP, V. Cartografar é acompanhar processos. In: PASSOS, E.; KASTRUP, V.; ESCÓSSIA, L. de (Orgs.). Pistas do método cartográfico: pesquisa intervenção e produção de subjetividade. Porto Alegre: Sulina, 2012.

BRASIL. Lei No 13.415, de 16 de fevereiro de 2017. Altera as Leis $n^{\circ} .9 .394$, de 20de dezembro de $1996 \quad$ [...]. Disponível em:<http://www.planalto.gov.br/ccivil_03/_ato20152018/2017/Lei/L13415.htm>.Acesso em: 31 Mar. 2017.

. Lei 11684/2008. Altera o art. 36 da Lei no 9.394, de 20 de dezembro de 1996, que estabelece as diretrizes e bases da educação nacional, para incluir a Filosofia e a Sociologia como disciplinas obrigatórias nos currículos do ensino médio. Disponível em: http://www.planalto.gov.br/ccivil 03/ ato20072010/2008/lei//11684.htm Acesso em 20.fev 2017.

CARVALHO, J. M. de. Forças armadas e política no Brasil. Rio de Janeiro: Jorge Zahar, 2005.

CERLETTI, A. O ensino de filosofia como problema filosófico. Belo Horizonte: Autêntica, 2009. 
COSTA, L. B. da. Cartografia: uma outra forma de pesquisar. LAV. Laboratório Digital do Laboratório de Artes Visuais. Disponível em: https://periodicos.ufsm.br/revislav/article/view/15111 Acesso em 30.out 2017.

COTRIM, G. Fundamentos da filosofia. São Paulo: Saraiva, 2000.

FOUCAULT, M. A hermenêutica do sujeito. 3. ed. São Paulo: Editora WMF Martins Fontes, 2010.

. Vigiar e Punir: nascimento da prisão. 42. ed. Petrópolis: Vozes, 2014.

GALLO, S. Filosofia e o Exercício do Pensamento Conceitual na Educação Básica.In: Educ. e Filos., Uberlândia, v. 22, n. 44, p. 55-78, jul./dez. 2008.

Metodologia do ensino de filosofia. Uma didática para o ensino médio. Campinas, SP: Papirus, 2012.

. KOHAN, W. O. Filosofia no ensino médio. Petrópolis: Vozes, 2000.

LARROSA, J. Notas sobre a experiência e o saber de experiência. Revista Brasileira de Educação, Rio de Janeiro, n. 19, p. 20-28, jan./abr. 2002.

Tecnologias do Eu e Educação. In: SILVA, Tomaz Tadeu da. 0 sujeito da educação. Estudos foucaultianos. Petrópolis: Vozes, 1994.

LIPOVETSKY, Gilles. Os tempos hipermodernos. São Paulo: Barcarolla, 2004. PIOL. A. S. Cartografias do ensino de filosofia no ensino médio: experiências em escolas públicas estaduais de Aracruz, ES. 2015. 182 f. Dissertação (Mestrado em Ensino na Educação Básica) - Programa de Pós-graduação em Ensino na Educação Básica, Universidade Federal do Espírito Santo, São Mateus, 2015.

PRADEAU, J. F. O sujeito antigo de uma ética moderna. In: Gros, F. (Org.). Foucault: a coragem da verdade. São Paulo: Parábola Editorial, 2004, p. 131153.

RANCIĖRE, J. 0 mestre ignorante. Cinco lições sobre a emancipação intelectual. Tradução de Lílian do Valle. Belo Horizonte: Autêntica, 2002.

SANTOS JR., F. N. dos; NEIRA, M. G. Olhares sobre a proposta de reorganização do currículo do ensino médio na rede estadual paulista. Revista Internacional de Formação de Professores. Itapetininga, v. 5, e020008, p. 119, $2020 . \quad$ Disponível em: https://periodicos.itp.ifsp.edu.br/index.php/RIFP/article/view/1824 Acesso em 01.jul 2020.

SAUTET, Marc. Um café para Sócrates: como a filosofia pode ajudar a compreender o mundo de hoje. 6. ed. Rio de Janeiro: José Olympio, 2003.

SAVIANI, Dermeval. Educação: do senso comum à consciência filosófica. 19ª.ed. São Paulo: Autores Associados, 2013. 
TOMAZETTI, E. Filosofia no Ensino Médio e seu professor: algumas reflexões. Educação, Santa Maria, v. 27, n 2, p. 69-75, 2002. Disponível em: http://cascavel.ufsm.br/revistas/ojs2.2.2/index.php/reveducacao/article/view/444 I23 Acesso em 10.Mai 2018.

Sobre os autores

\section{Fábio Pereira Barros}

Email: fabiosaojose2000@hotmail.com

Mestre pelo Programa de Pós-graduação em Ensino na Educação Básica, UFES/CEUNES. (2018). Graduado em Filosofia (Universidade Estadual de Santa Cruz-BA, 2010).

\section{Jair Miranda de Paiva}

Email: jmipaiva@gmail.com

Doutor em Educação (UFES, 2009). Pós-doutor em Educação (UERJ, 2018). Docente da Universidade Federal do Espírito Santo, campus São Mateus, Departamento de Educação e Ciências Humanas e do Programa de Pósgraduação em Ensino na Educação Básica, UFES/CEUNES. 